\title{
Pleomorphic Adenoma of the Hard and Soft Palate: A Case Presentation and Literature Review of Minor Salivary Gland Neoplasms
}

\author{
Panagiotis Saravakos ${ }^{1}$, Ioannis Kastanioudakis ${ }^{2}$, Afshin Fayyazi ${ }^{3}$, Oliver Reichel ${ }^{1}$ \\ ${ }^{1}$ Department of Otorhinolaryngology, Head and Neck Surgery, Siloah St. Trudpert Hospital, Pforzheim, Germany \\ ${ }^{2}$ Department of Otorhinolaryngology, Head and Neck Surgery, University Hospital of Ioannina, Ioannina, Greece \\ ${ }^{3}$ Institute of Pathology and Molecular Pathology, Pforzheim Hospital, Pforzheim, Germany \\ Email: psaravakos@yahoo.com, Afshin.Fayyazi@pathologie-pforzheim.de,o.reichel@siloah.de
}

How to cite this paper: Saravakos, P., Kastanioudakis, I., Fayyazi, A. and Reichel, O. (2016) Pleomorphic Adenoma of the Hard and Soft Palate: A Case Presentation and Literature Review of Minor Salivary Gland Neoplasms. International Journal of Otolaryngology and Head \& Neck Surgery, 5, 209214.

http://dx.doi.org/10.4236/ijohns.2016.56033

Received: August 26, 2016

Accepted: October 17, 2016

Published: October 20, 2016

Copyright $\odot 2016$ by authors and Scientific Research Publishing Inc. This work is licensed under the Creative Commons Attribution International License (CC BY 4.0).

http://creativecommons.org/licenses/by/4.0/

\section{Abstract}

Introduction: Minor salivary gland tumors are relatively rare, but have a higher chance of malignancy than major salivary gland tumors. The palate appears to be the most commonly involved site. The most frequent benign tumor is the pleomorphic adenoma. Case report: We report a case of a pleomorphic adenoma, which occurred in the hard and soft palate of a 34-year-old female and presented as an asymptomatic slow growing, painless mass. The patient was successfully treated with surgical excision. Discussion: Minor salivary gland tumors should be considered in the differential diagnosis of oral cavity and especially palate tumors. A histological examination is necessary due to the high percentage of malignancy.

\section{Keywords}

Minor Salivary Glands, Palate Tumor, Intraoral Tumors, Pleomorphic Adenoma

\section{Introduction}

The minor salivary glands are widely dispersed throughout the upper respiratory tract, including the palate, lip, pharynx, nasopharynx, larynx, parapharyngeal space and sinonasal cavities. The greatest densities of glands are found in the hard and soft palates, while they are not present in the gingival or the midline and anterior part of the hard palate [1]. The most common tumor of the palate is the pleomorphic adenoma, accounting for approximately $40 \%-52 \%$ of all palatal minor salivary gland tumors [2]-[4].

In our case presentation, we aim to summarize the incidence and clinical characteristics of minor salivary gland neoplasms (especially the pleomorphic adenomas) and to 
alert the medical community to consider these tumors in the differential diagnosis of oral cavity tumors, particularly in the palate.

\section{Case Report}

A 34-year-old female presented with a 4-week-history of mouth dryness and painless swelling at the hard and soft palate. Clinical examination revealed a firm, nodular, non-tender, $1 \mathrm{~cm}$ large mass. There were no other neck masses. The patient denied tobacco or alcohol consumption; the medical, surgical and family history was unremarkable. A magnetic resonance imaging (MRI) scan of the head and neck revealed a $1 \mathrm{~cm}$ mixed hyper-and hypo attenuated irregular lesion (Figure 1 and Figure 2). A contrast-enhanced computed tomography (CT) demonstrated an inhomogeneously enhanced mass and excluded a possible bone erosion. The tumor was surgically removed in its entity. The gross examination of the surgical specimen revealed a $1 \mathrm{~cm}$, encapsulated, partly solid, partly papillary epithelial tumor with a pseudo-capsule.

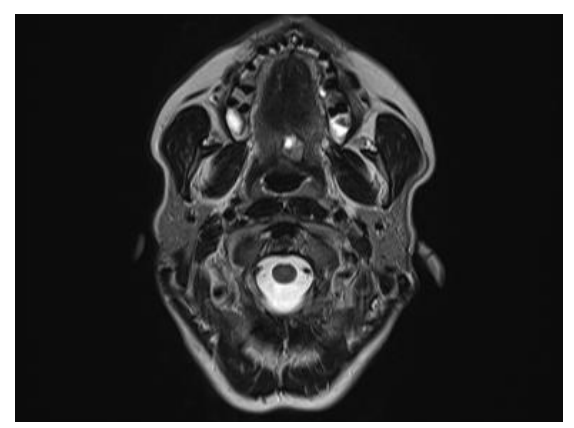

Figure 1. T2-weighted MRI in transversal plane showing the well demar- cated, mixed hyperintense and hypointense lesion of the palate.

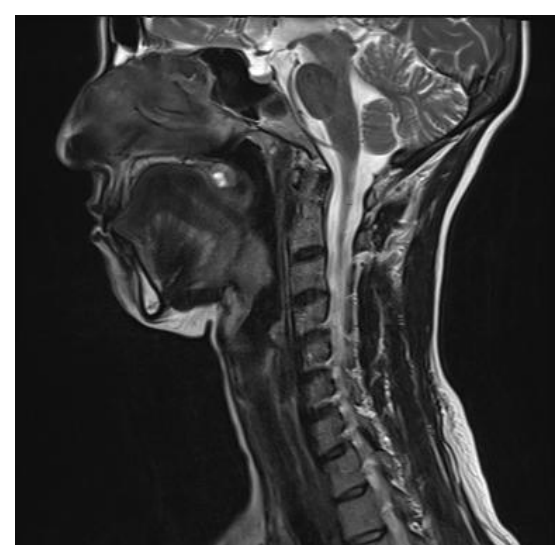

Figure 2. T2-weighted MRI in sagittal plane revealing a mass confined to the palate. Fibrous capsules appearing as hypointense on $\mathrm{T} 2$-weighted images are characteristic of pleomorphic adenoma. 


\section{Discussion}

The minor salivary glands account for $22 \%$ of all salivary gland neoplasms [5]. Unlike parotid and submandibular salivary gland tumors, tumors originating from the minor salivary glands have a greater chance of malignancy. A retrospective case-series study of 546 minor salivary gland tumors concluded that $56 \%$ of minor salivary gland tumors were benign, and $44 \%$ were malignant [2]. These results are consistent with other studies, which showed that $57.5 \%$ of intraoral minor salivary gland tumors were benign and $42.5 \%$ were classified as malignant or potentially malignant [4]. Concerning localization, the oral cavity is the most frequent site of minor salivary gland cancer, primarily appearing in the hard and soft palate, the lips and the buccal mucosa. 55\% of the setumors occur in the palate-mainly at the junction between the hart and soft palate-and $15 \%$ occur in the lips. More specifically, regarding palate tumors, a case-series study showed that these tumors are mainly benign ( $67 \%$ benign, $37 \%$ malignant). In addition, the upper lip is more frequently involved than the lower lip. The remaining tumors are distributed about equally among the other glands in the tongue, floor of the mouth, retromolar region, buccal mucosa and peritonsillar area [6].

The most common benign and malignant tumors of the minor salivary glands are presented in Table 1. Pleomorphic adenoma is the most common salivary gland tumor and accounts for about $60 \%$ of all salivary neoplasms [7]. About $80 \%$ of pleomorphic adenomas rise in the parotid, $10 \%$ in the submandibular gland and $10 \%$ in the minor salivary glands of the oral cavity, nasal cavity and paranasal sinuses, and the upper respiratory and alimentary tracts [8]. The reported annual incidence is $2.4-4.29$ per 100,000 people [7]. There is as light female predominance [4]. In the minor salivary glands, the incidence of pleomorphic adenoma ranges from 33\% - 70\% of all tumors [4] [9].

MRI with contrast agent is the diagnostic modality of choice for the imaging of palate tumors, as it allows for a determination of the extent and nature of the lesion and local spread of the tumor. On MRI-images, the borders of parotid and submandibular gland lesions often show lobulation, while those of palatal lesions are usually smooth [10]. A CT-scan (CT) can exclude a bone erosion [11]. In our case, MRI was primarily used to determine size and, more importantly, infiltration of the lesion into the surrounding tissues. We found the lesion to be a $1 \times 1 \mathrm{~cm}$ soft tissue dense mass, not involving adjacent tissues.

Table 1. The Commonest histological types of minor salivary gland tumors.

\begin{tabular}{cc}
\hline \multicolumn{2}{c}{ The Commonest minor salivary gland tumors } \\
\hline Benign & Malignant \\
Pleomorphic adenoma & Mucoepidermoid carcinoma \\
Canalicular adenoma & Adenoid cystic carcinoma \\
Papillary cystadenoma & Polymorphous low-grade adenocarcinoma \\
Ductal cystadenoma & Acinic cell adenocarcinoma \\
Sialadenoma papilliferum & Adenocarcinoma NOS (not otherwise specified)
\end{tabular}


Histologically, pleomorphic adenomas display great diversity of morphologic features and growth patterns. They usually contain a capsule (which may be in some cases poorly developed or absent), as well as epithelial and mesenchymal (myoepithelial) components (Figure 3). The epithelial component varies in cell types and usually forms sheets or duct-like structures. This presence of ducts or duct-like structures is the reason why the pleomorphic adenomas are called adenomas [12].

The differential diagnosis includes palatal abscess, odontogenic and non-odontogenic cyst, fibroma, lipoma, neurofibroma, neurilemmoma, condyloma acuminata, oral papilloma and squamous cell carcinoma [13]. Indicators for malignancy include the erosion of the overlying mucosa, bleeding or pain. The benign growth-like torus palatinus will be bony hard on palpation with an irregular appearance [13]. The soft tissue benign tumor can be differentiated through cytological/histopathological investigation like Fine-Needle-Aspiration Cytology or incisional biopsy.

Surgical excision is the treatment of choice and should be performed, since a rate of $1.9 \%-23.3 \%$ of malignant transformation is described in the literature [14]. Recurrences are rare in the minor salivary glands [15]. The primary goal of the surgical excision should be the complete removal of the tumor. We performed a complete excision of the tumor and overlying mucosa, and the surgical wound was closed with the advancement of adjacent mucosa. This produced an excellent result. The excised region can also be left to heal by secondary intention. Follow-up examinations are essential to quickly detect local recurrence. In our case, no recurrence has been noted after a period of 6 months.

\section{Conclusion}

In summary, this case demonstrates a case of pleomorphic adenoma occurring in a young female. Neoplasms in the minor salivary glands are relatively rare, but pleomorphic adenoma is the most common type of tumor. The treatment goal is the surgical excision of the tumor, considering the relative high rate of malignant transformation. Follow-up examinations are recommended in order to detect recurrences early.

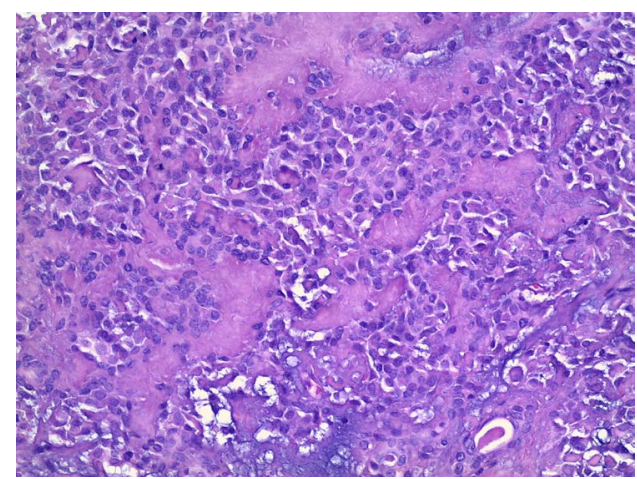

Figure 3. Epithelial cells forming sheets, among them hyalinized bulks can be seen (hematoxylin and eosin, magnification $10 \times 20$ ). 


\section{Ethical Approval}

This article does not contain any experimental studies with human participants or animals performed by any of the authors.

\section{Funding Source}

No funding was secured for this study.

\section{Financial Disclosure}

There are no financial relationships that could be broadly relevant to the work.

\section{Conflict of Interest}

The authors have no conflicts of interest to disclose.

\section{Informed Consent}

Informed consent was obtained from all individual participants included in the study. No identifying information about participants is available in the article.

\section{References}

[1] Hand, A.R., Pathmanathan, D. and Field, R.B. (1999) Morphological Features of the Minor Salivary Glands. Archives of Oral Biology, 44, S3-S10. http://dx.doi.org/10.1016/S0003-9969(99)90002-X

[2] Pires, F.R., Pringle, G.A., de Almeida, O.P. and Chen, S.Y. (2007) Intra-Oral Minor Salivary Gland Tumors: A Clinicopathological Study of 546 Cases. Oral Oncology, 43, 463-470. http://dx.doi.org/10.1016/j.oraloncology.2006.04.008

[3] Yih, W.Y., Kratochvil, F.J. and Stewart, J.C. (2005) Intraoral Minor Salivary Gland Neoplasms: Review of 213 Cases. Journal of Oral and Maxillofacial Surgery, 63, 805-810. http://dx.doi.org/10.1016/j.joms.2005.02.021

[4] Waldron, C.A., El-Mofty, S.K. and Gnepp, D.R. (1988) Tumors of the Intraoral Minor Salivary Glands: A Demographic and Histologic Study of 426 Cases. Oral Surgery, Oral Medicine, Oral Pathology, 66, 323-333. http://dx.doi.org/10.1016/0030-4220(88)90240-X

[5] Spiro, R.H. (1986) Salivary Neoplasms: Overview of a 35-Year Experience with $2807 \mathrm{~Pa}-$ tients. Head and Neck Surgery, 8, 177-184. http://dx.doi.org/10.1002/hed.2890080309

[6] Lucas, R.B. (1985) Pathology of the Tumors of the Oral Tissues. Journal of Oral and Maxillofacial Surgery, 43, 148.

[7] Andreasen, S., Therkildsen, M.H., Bjorndal, K. and Homoe, P. (2015) Pleomorphic Adenoma of the Parotid Gland 1985-2010: A Danish Nationwide Study of Incidence, Recurrence Rate, and Malignant Transformation. Head Neck, 38, E1364-E1369.

[8] Eveson, J.W. and Cawson, R.A. (1985) Salivary Gland Tumours. A Review of 2410 Cases with Particular Reference to Histological Types, Site, Age and Sex Distribution. The Journal of Pathology, 146, 51-58. http://dx.doi.org/10.1002/path.1711460106

[9] Rivera-Bastidas, H., Ocanto, R.A. and Acevedo, A.M. (1996) Intraoral Minor Salivary Gland Tumors: A Retrospective Study of 62 Cases in a Venezuelan Population. Journal of Oral Pathology \& Medicine, 25, 1-4. http://dx.doi.org/10.1111/j.1600-0714.1996.tb01214.x 
[10] Kakimoto, N., Gamoh, S., Tamaki, J., Kishino, M., Murakami, S. and Furukawa, S. (2009) $\mathrm{CT}$ and MR Images of Pleomorphic Adenoma in Major and Minor Salivary Glands. European Journal of Radiology, 69, 464-472. http://dx.doi.org/10.1016/j.ejrad.2007.11.021

[11] Lingam, R.K., Daghir, A.A., Nigar, E., Abbas, S.A. and Kumar, M. (2011) Pleomorphic Adenoma (Benign Mixed Tumour) of the Salivary Glands: Its Diverse Clinical, Radiological, and Histopathological Presentation. British Journal of Oral and Maxillofacial Surgery, 49, 14-20. http://dx.doi.org/10.1016/j.bjoms.2009.09.014

[12] Wu, Y.C., Wang, Y.P., Cheng, S.J., Chen, H.M., Sun, A. and Chang, J.Y. (2016) Clinicopathological Study of 74 Palatal Pleomorphic Adenomas. Journal of the Formosan Medical Association, 115, 25-30. http://dx.doi.org/10.1016/j.jfma.2015.09.008

[13] Gupta, M. and Gupta, M. (2013) Pleomorphic Adenoma of the Hard Palate. BMJ Case Report.

[14] Ethunandan, M., Witton, R., Hoffman, G., Spedding, A. and Brennan, P.A. (2006) A Typical Features in Pleomorphic Adenoma: A Clinicopathologic Study and Implications for Management. International Journal of Oral \& Maxillofacial Surgery, 35, 608-612. http://dx.doi.org/10.1016/j.ijom.2006.02.009

[15] Hickman, R.E., Cawson, R.A. and Duffy, S.W. (1984) The Prognosis of Specific Types of Salivary Gland Tumors. Cancer, 54, 1620-1624. http://dx.doi.org/10.1002/1097-0142(19841015)54:8<1620::AID-CNCR2820540824>3.0.CO; $\underline{2-\mathrm{I}}$

Submit or recommend next manuscript to SCIRP and we will provide best service for you:

Accepting pre-submission inquiries through Email, Facebook, LinkedIn, Twitter, etc.

A wide selection of journals (inclusive of 9 subjects, more than 200 journals)

Providing 24-hour high-quality service

User-friendly online submission system

Fair and swift peer-review system

Efficient typesetting and proofreading procedure

Display of the result of downloads and visits, as well as the number of cited articles

Maximum dissemination of your research work

Submit your manuscript at: http://papersubmission.scirp.org/

Or contact ijohns@scirp.org 